\title{
Study of detonation initiation in kerosene-oxidizer mixtures in short tubes
}

\author{
J. Kindracki
}

Received: 5 December 2011 / Revised: 14 March 2014 / Accepted: 28 June 2014 / Published online: 25 July 2014

(C) The Author(s) 2014. This article is published with open access at Springerlink.com

\begin{abstract}
The paper describes experimental studies of detonation initiation in a kerosene-oxidizer mixture in a short test tube. The aim of the study is to determine the minimum diameter of the tube and the minimum level of energy that enables direct initiation of the detonation. Knowledge about these values will inform the design of a jet engine combustion chamber in which thermal energy will be generated by a rotating detonation process. The test tube and the oxidizer inside the tube were heated using specially designed heaters installed outside of the tube. The heated oxidizer provided thermal conditions similar to the conditions for a compressor with small to medium static pressure. The study was conducted for four different tube diameters and for various energies of initiation. As a result, measurements of pressure waveforms were obtained for various cases of fuel injection, which were then compared against the results of the shock wave generated by the initiator. This study provides a value for the energy (the pressure of the mixture in the initiator), which provided direct initiation of detonation for a keroseneoxidizer mixture. Different tube diameters led to the initiation of detonation for various oxygen-nitrogen compositions as an oxidizer.
\end{abstract}

Keywords Detonation initiation - Rotating detonation . Combustion chamber

Communicated by N. N. Smirnov and E. Timofeev.

J. Kindracki $(\bowtie)$

Institute of Heat Engineering, Warsaw University of Technology,

Nowowiejska Str. 21/25 00-660, Warsaw, Poland

e-mail: jkind@itc.pw.edu.pl

URL: http://www.itc.pw.edu.pl

\section{Introduction}

In recent years, detonation as a combustion process has attracted greater attention. This is due to an increasing number of serious attempts to use it as a combustion process in jet and rocket propulsion. The most widely studied detonation applications are the Pulse Detonation Engine (PDE) and the Rotating Detonation Engine (RDE). In the last few decades, several PDE models running on gas and liquid fuels were built and tested. Roy et al. [1] reviewed a number of PDE engine design solutions, with different systems controlling the operation of the combustion chamber. Rasheed et al. [2] went a step further, describing the successful application of the study on an 8-tube PDE design as the can-annular combustion chamber working with a gas turbine. They used a stoichiometric mixture of ethylene-air at a mass flow rate of $3.628 \mathrm{~kg} / \mathrm{s}$, and a turbine speed of $18,500 \mathrm{rpm}$. Power of 257 $\mathrm{kW}$ was achieved, and the tests lasted for at least $5 \mathrm{~min}$.

Extensive tests on the RDE engine have a shorter history, despite the fact that attempts at spin detonation in an axisymmetric channel were first conducted in the late 1950s by Voitsekhovskii et al. [3] and Voitsekhovskii [4]. A rotating detonation wave was obtained using acetylene and oxygen as the combustible mixture. The same research attempted to repeat the findings by Nichols et al. [5], but without positive results. In his final report, Voitsekhovskii concluded that although they did not achieve a positive outcome, it was not an impossible aim. The next major publication dates are around the year 2000. Bykovskii et al. [6] published images obtained from using a velocity compensation method for mixtures of acetylene with oxygen and hydrogen with air in a cylindrical chamber. The sudden growth of interest in rotating detonation can be dated to 2000, with the publication of many experimental works, e.g., Wolanski et al. [7], Kindracki et al. [8], Bykovskii et al. [9-11]. 
In these studies, most of the experiments reported were conducted with gaseous fuels. To utilize detonation, as an alternative to deflagration, the use of liquid fuels is needed. The scale of the difficulties involved in the detonation of heterogeneous mixtures is illustrated by the problems associated with it. In the papers of Bykovskii et al. [12] and Vasil'ev et al. [13] the authors state that for a mixture of propane-air 340 $\mathrm{kJ}$ of energy is required to initiate detonation. For a mixture of kerosene-air the energy needed is much higher. According to the research of Alekseev et al. [14] and Papavassiliou et al. [15] this value of energy is dependent on the size of the droplets of liquid fuel.

The first successful tests of rotating detonation in heterogeneous mixtures were published by Bykovskii et al. [12]. Their article describes rotating detonation using liquid kerosene with an oxidizer. The authors used, as the oxidizing mixture, a 1:1 mixture of oxygen-nitrogen for the initiation and propagation of detonation in a chamber with a diameter of $306 \mathrm{~mm}$ and a channel width of $16.5 \mathrm{~mm}$. An explosive material with a mass of $0.2 \mathrm{~g}$ was used to initiate the process of rotating detonation.

Kailasanath [16] described the development of research on the detonation of liquid fuel in a broad review article. In the paper, he focused on the problems of determining the minimum initiation energy and a range of occurrence of detonation. In addition, he considered the effect of the size of fuel droplets on detonation. These problems have a significant impact on the design of PDE engines running on liquid hydrocarbon fuels.

The issue of the amount of energy required to initiate detonation was presented by Alekseev et al. [17]. In their work, they presented the results of detonation initiation in an unconfined gasoline spray (volume of approx. 1,100 $\mathrm{m}^{3}$ ), and concluded that the minimum energy of initiation also depends on the kind of initiator. The study of detonation for a number of aviation fuels (Avgas, JP8, JP10) is also described by Schauer et al. [18]. Detonation was initiated in a tube with a length of $1.52 \mathrm{~m}$, fitted with $1.22 \mathrm{~m}$ Schelkin-type spirals. As for the initiator, an additional $50.1 \mathrm{~mm}$ diameter tube attached to the test tube was used. In the test, the supplied fuel was premixed with part of the air and the rest of the air was heated up to $360 \mathrm{~K}$. The deflagration to detonation transition (DDT) was only observed when fuel was correctly mixed with air. In other cases, where the fuel droplets were too large or the fuel-air mixture was inhomogeneous, there was no DDT.

Sorin and Bauer [19] presented their results of research on THDCPD-exo/Air Mixtures $\left(\mathrm{C}_{10} \mathrm{H}_{16}\right)$ for pressures in the range of 1-3 bar. The experiments were conducted in a 5 $\mathrm{m}$ long steel tube heated up to $375 \mathrm{~K}$. Vaporized fuel was injected into the tube and mixed with air. The detonation velocity and the cell width measurements were carried out, and the results were similar to the calculations. It was also found that the fuel used in the studies required the same level of energy for detonation initiation as the propane-air mixture. Dean et al. [20] presented a study on the ignition of kerosene at elevated temperatures (340-373 K) in a $5 \mathrm{~m}$ long tube with a diameter of $76 \mathrm{~mm}$. Ignition delay time was measured for the incident and reflected shock waves and different mixture compositions. They found a significant reduction in the activation energy for the cases in which the temperature behind the shock wave was greater than 1,400 K.

Frolov and Aksenov [21] described detonation tests in a kerosene-air mixture for a tube with a length of $3 \mathrm{~m}$ and a diameter of $52 \mathrm{~mm}$. Part of the tube was heated to a maximum temperature of $400 \mathrm{~K}$. In order to reduce the path of DDT, Schelkin-type spirals were fitted to the initial section of the tube. Pre-mixed fuel and air were obtained using an air-assisted fuel atomizer to ensure small droplets of fuel (5-10 $\mu \mathrm{m}$ in diameter). A pre-detonator was used as an initiator; vaporized fuel mixed with air was ignited using a spark plug with energy in the range of 5-700 J. The results of the experiments determined that the use of this method of detonation initiation produces DDT at a distance of $2 \mathrm{~m}$ from the point of ignition for a very low ignition energy of $5 \mathrm{~J}$ (as mentioned above, about $340 \mathrm{~kJ}$ of energy is required for the direct initiation of spherical detonation).

Another way to reduce the amount of energy required to initiate detonation in a heterogeneous mixture was examined by Imbert et al. [22]. The paper presents the results of research on liquid fuel additives that increase the sensitivity of the mixture. The study was conducted for heptane with the addition of nitromethane $\left(\mathrm{CH}_{3} \mathrm{NO}_{2}\right)$ and hydrogen peroxide $\left(\mathrm{H}_{2} \mathrm{O}_{2}\right)$. However, the nitromethane addition only slightly increased the sensitivity of the mixture, whereas even a small (1\%) addition of hydrogen peroxide reduced the induction time by a factor of four.

Austin and Shepherd [23] describe detonation experiments in JP-10 mixtures for a tube with an internal diameter of $280 \mathrm{~mm}$ and a length of $7.3 \mathrm{~m}$. They provided data on the cell size for two kinds of mixtures: vapor-phase JP-10 and decomposed JP-10 surrogate. As an oxidizer, a mixture of oxygen and nitrogen was used. They found the average cell size for the JP-10-air mixture to be $60.4 \mathrm{~mm}$, which is comparable with the measurements provided by Akbar et al. [24]. Moreover, this result suggests that propane fuel can be used in initial research of detonation engines. Additionally, they estimated the critical initiation energy for a planar initiation source for oxygen and air as an oxidizer. This energy increases by two orders of magnitude if kerosene is detonated in air.

Wen et al. [25] described detonation experiments in JP8 oxygen mixtures for a tube with an internal diameter of $101.6 \mathrm{~mm}$ and a length $1.143 \mathrm{~m}$ at elevated temperatures. They provided data for the fuel vapor phase as a function of temperature and pressure in the range of $1 \div 4$ bar. The fully vaporized temperature of the fuel was about $380 \mathrm{~K}$ for 
Table 1 Dimensions of the tubes used in the experiment

\begin{tabular}{lllll}
\hline Tube no. & 1 & 2 & 3 & 4 \\
\hline Internal diameter $(\mathrm{mm})$ & 24.5 & 34.7 & 44 & 55 \\
Length $(\mathrm{mm})$ & 1,050 & 1,050 & 1,050 & 1,050 \\
Volume $\left(\times 10^{-3} \mathrm{~m}^{3}\right)$ & 0.495 & 0.993 & 1.596 & 2.494 \\
Heater number $\times$ power $(\mathrm{W})$ & $5 \times 350$ & $5 \times 700$ & $4 \times 850$ & $5 \times 800$ \\
\hline
\end{tabular}

ambient pressure. Detonation initiation with a short DDT run-up distance was observed only for fully vaporized JP-8 and oxygen (for temperature $413 \mathrm{~K}$ ). A decrease in initial temperature to $393 \mathrm{~K}$ caused a decrease in the fuel vapor phase (to $95 \%$ ) and an increase in the DDT run-up distance.

The present paper describes experiments that were conducted in order to design a detonation chamber (for an RDE engine) with the use of rotating detonation. Development of a rotating detonation process for liquid fuel will be a key issue in the implementation of this propulsion system for use in the aerospace industry. The initiation of detonation is one of the most difficult problems to overcome. This is due to both the large energy required to initiate and technical implementation challenges. The matter is complicated by the fact that air is usually an oxidizer for aircraft propulsion. The multiple re-use of air increases the initiation energy compared with pure oxygen oxidizer. Another problem is the proper fragmentation and rapid evaporation of liquid fuel jets in order to produce an appropriate mixture. The present studies provide the first data for proper design of the combustion chamber of an RDE engine for liquid kerosene. The test tube was specially designed to obtain conditions approximating those in a real combustion chamber. Therefore, it was decided to use the direct injection of liquid fuel (without pre-evaporation) into the test tube to fully reflect what occurs in a real combustion chamber. More information on the design and concept of an RDE chamber can be found in the papers $[8,26]$.

\section{The research stand}

The main element of the test bench was a steel tube with a circular cross-section and $1,050 \mathrm{~mm}$ in length, installed in a vertical position. Four tubes of different diameters were used, as described in Table 1. The upper end of the tube was closed by a fuel injector. The lower end of the tube was closed by a drain valve. In some of the experiments, the axial gas initiator was replaced with a valve. The tube was equipped with several slots for the installation of pressure and temperature sensors as well as the oxidizer supply port. Figure 1 shows a schematic diagram and a view of the test bench.

Each tube was equipped with a heater used to heat the oxidizer to a chosen temperature. Heaters were connected to a thermo-regulator to control the process of heating the tube and maintain a stable temperature at the specified level. The parameters of the heaters are listed in Table 1. A thermoregulator of the ESM 4420.5.20.0.1 type was used with a K-type thermocouple installed on the outer wall of the tube in order to measure the actual temperature values.

\subsection{Measurement system}

The measuring system consisted of two subsystems: the first for measuring the temperature inside the tube and the second for measuring the pressure during the experiment. The temperature measurements inside the tube were conducted continuously (from the beginning to the end of each test day) by K-type thermocouples, a thermocouple amplifier and a measuring card, National Instruments USB 6259. The temperature inside the tube was measured at three points: at some distance from both ends of the tube and in the middle of its length. This measurement system allowed the selection of individual power for each of the heaters in order to maximize the oxidizer temperature uniformly along the entire tube. To change the power of the individual heaters, additional resistance was added to each heater. The temperatures of the heaters and of the pressure sensor casings were also monitored to prevent the tube equipment overheating.

The pressure measurement subsystem consisted of Kistler 603B transducers, amplifiers and a 4-channel measuring card, NI PCI 6115, with a sampling frequency of up to 10 $\mathrm{MHz}$ for each measurement channel. To ensure the proper measurement of pressure and to prevent damage, the sensors were installed in special sockets cooled by water, which allowed the temperature sensors to be kept in the range of 293-303 K. Additionally, the front faces of the pressure sensors were protected by a thin layer of silicon grease. The NI PCI 6115 card was also used to control the injection process (onset and duration) and the time of ignition initiation in the initiator.

Figure 2 shows the location of the pressure and temperature sensors for each tube. For the first two tubes, two pressure transducers were used, while the tubes with the internal diameters of 44 and $55 \mathrm{~mm}$ had three pressure sensors installed. This was done in order to increase the accuracy of the measurements. Differences in the location of transducers for each tube resulted from the size and distribution of the heaters.

\subsection{The injection system}

The injection system consisted of the following parts: an electrically controlled plain orifice injector, a fuel tank and a tank of nitrogen. A simple injector design allowed precise control of the fuel dose injected directly into the tube at a suitably chosen time. The fuel injector was fed from a small tank with a volume of several cubic centimetres, using inert gas 
(a)

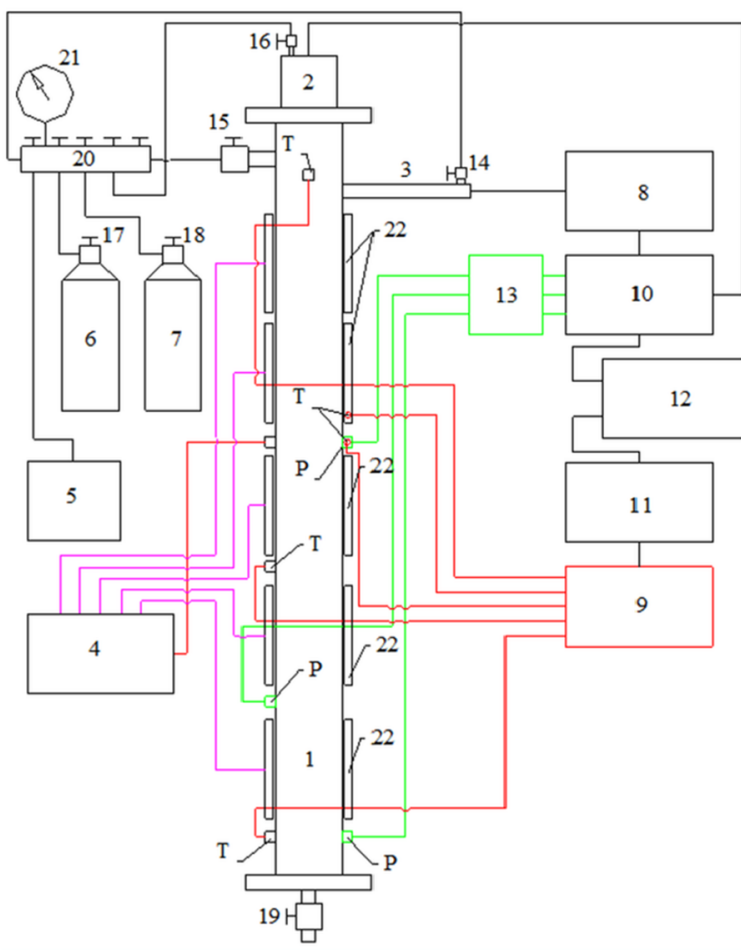

Fig. 1 Experimental setup: a schematic diagram of the research stand: $P$ pressure transducers, $T$ thermocouples, 1 tube; 2 fuel injector, 3 initiator, 4 temperature control unit, 5 vacuum pump, 6 bottle with oxidizer, 7 bottle with nitrogen, 8 ignitron unit, 9 thermocouple amplifier,

(b)

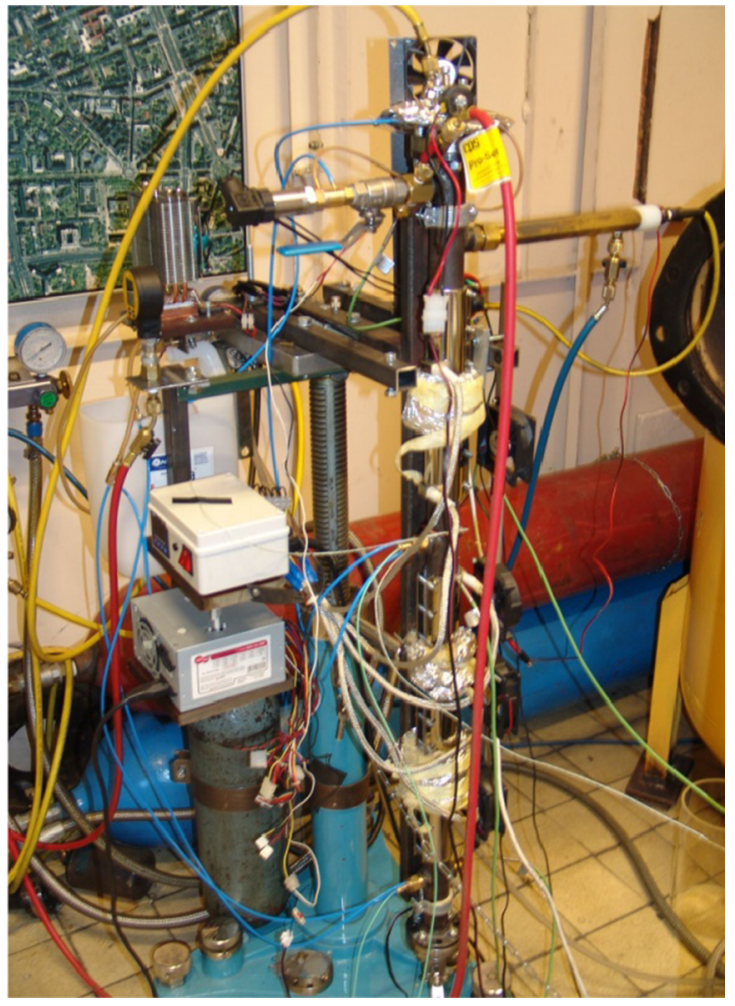

10,11 acquisition card, 12 computer, 13 pressure transducers amplifiers, 14-19 ball valves, 20 pressure manifold, 21 manometer, 22 heaters; b view of the facility

(b)

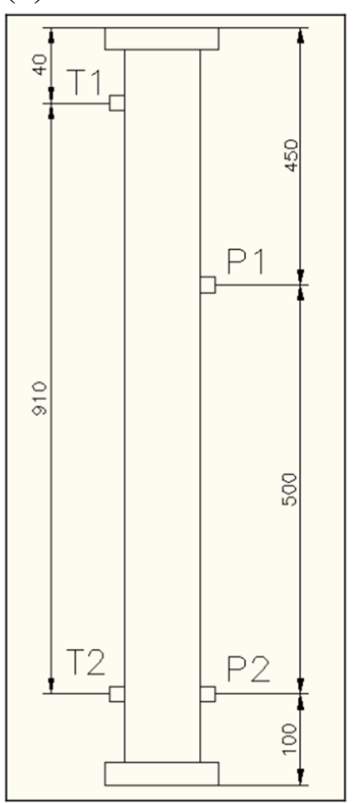

(c)

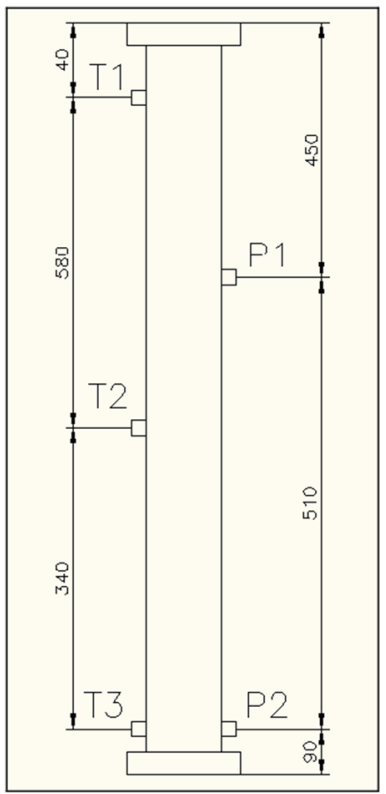

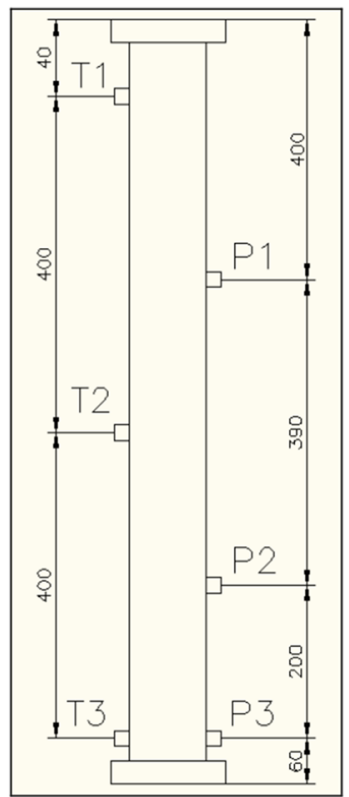


(nitrogen) to pump the fuel to the injector. Nitrogen pressure was, typically, 6 bar. The supply system was simple, reliable and safe because the amount of fuel on the test bench was minimized. The correlation between the mass flow rate of the fuel and nitrogen pressure was determined during preliminary tests. Due to the time delay in opening and closing, the fuel mass injected into the tube can be represented by the third degree polynomial function of time for an injection pressure of 6 bar:

$$
\begin{aligned}
m(g)=5 & \times 10^{-6} \times t^{3}\left(\mathrm{~ms}^{3}\right)-6 \times 10^{-4} \times t^{2}\left(\mathrm{~ms}^{2}\right) \\
& +2.91 \times 10^{-2} \times t(\mathrm{~ms})-6.52 \times 10^{-2}
\end{aligned}
$$

The above relationship enabled an approximate determination of the composition of the mixture. The error of the determined mixture composition was of the order of $\pm 10 \%$. However, it needs to be noted that it is impossible to exactly determine the amount of evaporated fuel and took part in the chemical reactions at the time of detonation wave propagation. Therefore, determining the mixture composition was only a qualitative process.

\subsection{The initiation system}

To initiate the process of detonation in the test tube a gas initiator was used. It was filled with a stoichiometric mixture of acetylene and oxygen at the specified pressure. The initiation mixture was prepared in a special tank, using the partial pressure method, at least $24 \mathrm{~h}$ before the experiment. The uncertainty for this method is $\pm 1 \%$ for the equivalence ratio. Pressure change in the initiator allowed changes to be made in the energy used to initiate the process. Three initiator designs were used. They are listed in Table 2 and presented in Fig. 3.

Installation of the initiator was possible at two positions: perpendicular to the tube at a distance of $100 \mathrm{~mm}$ from the injector and axially mounted to the base of the tube. The initiator and tube volumes were separated by a thin plastic membrane with a thickness of $100 \mu \mathrm{m}$, which was destroyed during each experiment. The mixture was initiated by the spark plug and the control system. When the axial initiator was installed to the lower end of the tube, the tube was inverted by 180 degrees to maintain the same distance between the initiator and pressure sensors. This way it was possible to directly compare the results achieved using different initiators. Figure $3 \mathrm{~d}$ and e shows the locations of pressure transducers and thermocouples for all initiator configurations. In all subsequent figures where pressure histories are presented, the same order of pressure sensors is used.

The amount of chemical energy stored in the initiator was estimated using the lower heat value for acetylene as a fuel and the initial conditions of the mixture. The results are presented in Table 2. It is to be noted that the actual available

\begin{tabular}{|c|c|c|c|c|}
\hline & 1 & 2 & 3 & 4 \\
\hline \multicolumn{5}{|l|}{ Initiator \tube number } \\
\hline No. 1 Perpendicular small & Yes & Yes & Yes & Yes \\
\hline No. 2 Perpendicular large & No & No & No & Yes \\
\hline No. 3 Axial & No & Yes & Yes & Yes \\
\hline \multicolumn{5}{|l|}{ Initiator (diameter/length) (mm) } \\
\hline No. 1 Perpendicular small & $10 / 280$ & $10 / 280$ & $10 / 280$ & $10 / 280$ \\
\hline No. 2 Perpendicular large & - & - & - & $20 / 240$ \\
\hline No. 3 Axial & - & $34.7 / 65$ & $44 / 65$ & $55 / 65$ \\
\hline \multicolumn{5}{|l|}{ Volume ratio (tube/initiator) } \\
\hline No. 1 Perpendicular small & 22.5 & 45.15 & 72.57 & 113.4 \\
\hline No. 2 Perpendicular large & - & & & 33.07 \\
\hline No. 3 Axial & - & 16.15 & 16.14 & 16.14 \\
\hline \multicolumn{5}{|c|}{$\begin{array}{l}\text { Shock wave mean velocity }(\mathrm{m} / \mathrm{s}) \text { (created by initiator for } 3 \text { bar } \\
\text { in the initiator) }\end{array}$} \\
\hline No. 1 Perpendicular small & 875 & $740^{*}$ & 580 & 520 \\
\hline No. 2 Perpendicular large & - & - & - & 730 \\
\hline No. 3 Axial & - & 1,000 & 1,100 & 1,100 \\
\hline \multicolumn{5}{|c|}{$\begin{array}{l}\text { Available chemical energy }(\mathrm{J}) \text { (for initial pressure inside } \\
\text { initiator } 3 \text { bar) }\end{array}$} \\
\hline No. 1 Perpendicular small & 980 & 980 & 980 & 980 \\
\hline No. 2 Perpendicular large & - & - & - & 3,362 \\
\hline No. 3 Axial & - & 1,803 & 4,735 & 7,215 \\
\hline
\end{tabular}

Table 2 Initiation devices used in the experiments

* Value for 4 bar in the initiator

chemical energy was reduced by approximately $30-50 \%$. The reduction in energy originated from the following phenomena: dissociation losses, wall heat flux losses, energy loss linked to the bursting of membranes, conversion of fuel energy to shock wave energy, etc. The energy reduction value was determined by comparing the chemical energy and the energy of the shock and detonation waves.

\section{Experimental results}

The study was conducted for nine different oxygen-nitrogen compositions, considering pure oxygen and air as oxidizers. The research began with pure oxygen as an oxidizer for the smallest diameter tube, then switched to $90 \%$ (by volume) oxygen and $10 \%$ nitrogen. Changes in oxidizer took place successively with a $10 \%$ stepwise change in oxygen content in the mixture until the composition of air was reached.

For a given tube, experiments were carried out until a combination of tube diameter-oxidizer was found for which no direct initiation of detonation was obtained. At this point, the experiments were stopped, the tube was changed for a larger one, and the research continued. In the experiments, various energies of initiation were examined, which were changed by changing the initial pressure in the initiator. It was also 
(a)

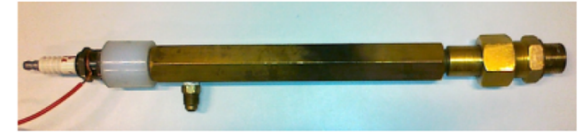

(b)

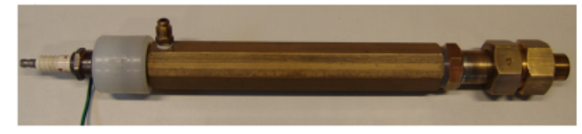

(c)

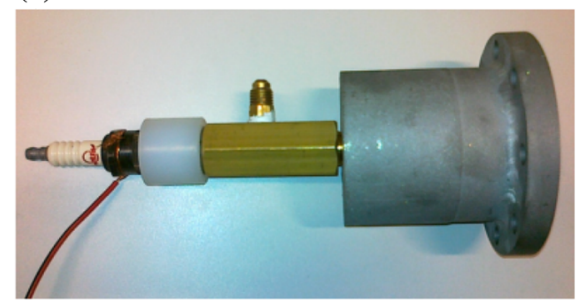

(d)

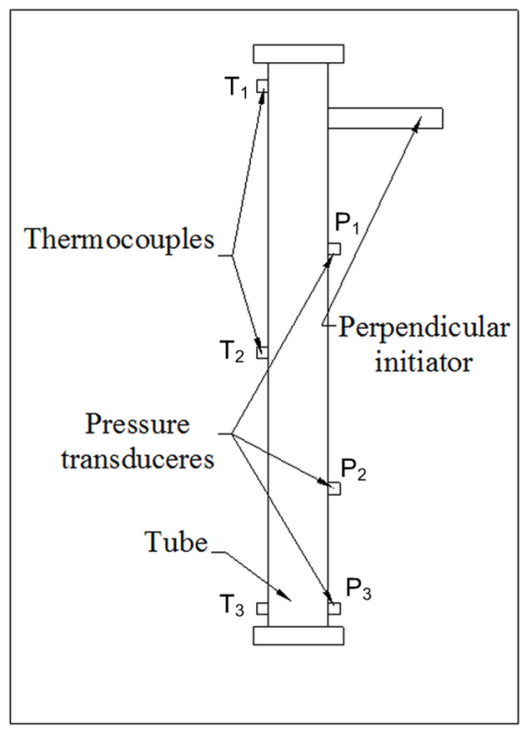

(e)

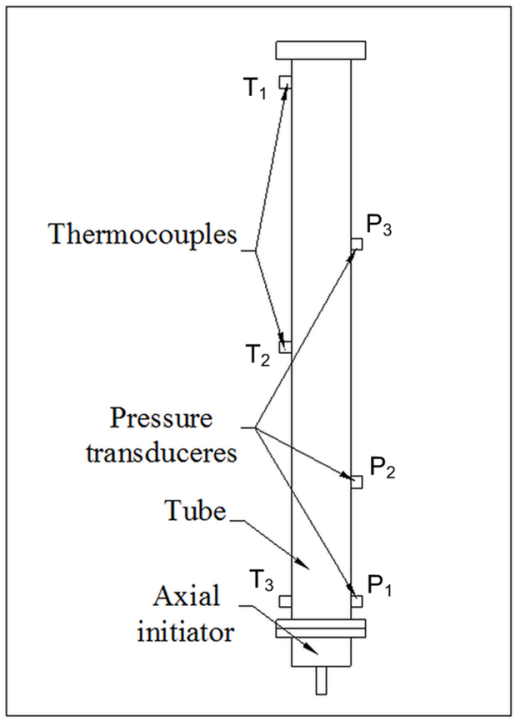

Fig. 3 The initiators: a perpendicular small $(\phi 10 / 280 \mathrm{~mm})$; b perpendicular large $(\phi 20 / 240 \mathrm{~mm})$; c axial $\left(\phi \mathrm{d}_{\text {tube }} / 65 \mathrm{~mm}\right)$; d assembly of perpendicular initiators; e assembly of axial initiator

possible to change the duration of injection (composition of the mixture), and also to change the time between the injection of liquid fuel and the initiating mixture in the initiator. By changing the delay time between injection and ignition within 100-4000 ms, the degree of evaporation of fuel, and its penetration and mixing with the oxidizer for the entire length of tube research were changed.

In the paper some characteristic cases of experiments for each of the tubes are described. Their parameters are listed in Table 3. Two kinds of experiments were conducted: calibration and initiation. The first was concerned with the testing of the initiator. In the tests, the initiator being ignited was connected to the tube filled only with oxidizer. This allowed the determination of the velocity (energy) of the shock wave generated by the initiator. The second type of experiment was designed to study the initiation of detonation in the mixture under study.

As mentioned above, the tube was heated to the desired temperature in the range of 400-465 K. This allowed thermal conditions to be achieved that are similar to the conditions in a real engine before the combustion chamber (compression ratio of about 6). A typical temperature history used on the test bench is shown in Fig. 4. Measurements of these values took place at a frequency of $10 \mathrm{~Hz}$. The period of heating of the tube to a certain temperature lasted, depending on the desired temperature and tube diameter, from 60 to 90 $\mathrm{min}$. After this time, the temperature was stable and allowed experiments to be performed. Single peaks in the temperature history inside the tube shown in Fig. 4 correspond to individual experiments. A sudden temperature drop is visible following each experiment (especially on the green and blue curves), corresponding to the exhaust gas discharge from the tube and its flushing. As mentioned earlier, the average temperature of the oxidizer in the tube was 400-465 K, depending on the experiment. The wall temperature at the ends of the tube differed by about $20-50 \mathrm{~K}$; the top end temperature was higher and the bottom one lower than the average. This was due to the vertical tube installation and the occurrence of natural convection. The mentioned temperature difference affected the initiation of detonation when the tube temperature was close to the self-ignition temperature of kerosene, which is equal to about $480 \mathrm{~K}$, as shown in Fig. $8 \mathrm{~d}$, where the self-ignition occurred before the initiation impulse. For most cases in the experiments, the difference recorded between the two extreme locations should not affect the detonation initiation. The upper part of the graph in Fig. 4 shows the temperature on the housing pressure sensor. As can be seen, during the experiments this value did not change by more than $10 \mathrm{~K}$, which allowed the measurements of the sensor to be under the same environmental conditions.

\subsection{Theoretical calculation}

Before the experimental studies were performed, Stanjan software $[27,28]$ was used to calculate the velocity of detonation. Calculations were carried out with the assumption of chemical equilibrium, the absence of heat exchange with the environment, and the following initial conditions of the mixture: temperature of $430 \mathrm{~K}$ and pressure of 1 bar. The composition of the oxidizer changed from pure oxygen through different oxygen-nitrogen mixtures up to pure air, and combustible mixtures varied from lean to 
Table 3 parameters of described experiments

\begin{tabular}{|c|c|c|c|c|c|c|}
\hline $\begin{array}{l}\text { Tube } \\
(\mathrm{mm})\end{array}$ & $\begin{array}{l}\text { Type of } \\
\text { experiment }\end{array}$ & Oxidizer & Type of initiator & $\begin{array}{l}\text { Initiator pressure (bar)/ } \\
\text { shock strength-Mach } \\
\text { number (only for } \\
\text { calibration case) }\end{array}$ & $\begin{array}{l}\text { Ignition delay (ms) } \\
\text { (time between injection } \\
\text { and ignition) }\end{array}$ & Case number \\
\hline \multirow[t]{8}{*}{24.5} & Calibration & $100 \% \mathrm{O}_{2}$ & Small, perpendicular & $3 / 2.38$ & - & 39 \\
\hline & Initiation & $100 \% \mathrm{O}_{2}$ & Small, perpendicular & 2 & 500 & 25 \\
\hline & Initiation & $90 \% \mathrm{O}_{2}+10 \% \mathrm{~N}_{2}$ & Small, perpendicular & 3 & 500 & 29 \\
\hline & Initiation & $80 \% \mathrm{O}_{2}+20 \% \mathrm{~N}_{2}$ & Small, perpendicular & 2 & 500 & 33 \\
\hline & Initiation & $70 \% \mathrm{O}_{2}+30 \% \mathrm{~N}_{2}$ & Small, perpendicular & 1 & 500 & 38 \\
\hline & Initiation & $50 \% \mathrm{O}_{2}+50 \% \mathrm{~N}_{2}$ & Small, perpendicular & 3.8 & 500 & 42 \\
\hline & Initiation & $50 \% \mathrm{O}_{2}+50 \% \mathrm{~N}_{2}$ & Small, perpendicular & 3.75 & 1,500 & 44 \\
\hline & Initiation & $40 \% \mathrm{O}_{2}+60 \% \mathrm{~N}_{2}$ & Small, perpendicular & 2.65 & 20 & 67 \\
\hline \multirow[t]{5}{*}{34.7} & Calibration & $60 \% \mathrm{O}_{2}+40 \% \mathrm{~N}_{2}$ & Small, perpendicular & $4 / 1.84$ & - & 80 \\
\hline & Initiation & $60 \% \mathrm{O}_{2}+40 \% \mathrm{~N}_{2}$ & Small, perpendicular & 4 & 1,000 & 73 \\
\hline & Initiation & $50 \% \mathrm{O}_{2}+50 \% \mathrm{~N}_{2}$ & Small, perpendicular & 4 & 1,000 & 75 \\
\hline & Initiation & $50 \% \mathrm{O}_{2}+50 \% \mathrm{~N}_{2}$ & Small, perpendicular & 3 & 1,000 & 98 \\
\hline & Initiation & $40 \% \mathrm{O}_{2}+60 \% \mathrm{~N}_{2}$ & Small, perpendicular & 3.77 & 1,500 & 89 \\
\hline \multirow[t]{6}{*}{44} & Calibration & $40 \% \mathrm{O}_{2}+60 \% \mathrm{~N}_{2}$ & Small, perpendicular & $3 / 1.42$ & - & 113 \\
\hline & Initiation & $40 \% \mathrm{O}_{2}+60 \% \mathrm{~N}_{2}$ & Small, perpendicular & 3 & 2,900 & 30 \\
\hline & Initiation & $30 \% \mathrm{O}_{2}+70 \% \mathrm{~N}_{2}$ & Small, perpendicular & 3 & 2,900 & 140 \\
\hline & Calibration & Air & Axial & $3 / 2.79$ & - & 231 \\
\hline & Initiation & Air & Axial & 3 & 400 & 232 \\
\hline & Initiation & Air & Axial & 3 & 400 & 233 \\
\hline \multirow[t]{6}{*}{55} & Calibration & $30 \% \mathrm{O}_{2}+70 \% \mathrm{~N}_{2}$ & Small, perpendicular & $3 / 1.27$ & - & 253 \\
\hline & Initiation & $30 \% \mathrm{O}_{2}+70 \% \mathrm{~N}_{2}$ & Small, perpendicular & 3.3 & 1,900 & 183 \\
\hline & Calibration & $30 \% \mathrm{O}_{2}+70 \% \mathrm{~N}_{2}$ & large, perpendicular & $3 / 1.85$ & - & 186 \\
\hline & Initiation & $30 \% \mathrm{O}_{2}+70 \% \mathrm{~N}_{2}$ & large, perpendicular & 3 & 1,900 & 190 \\
\hline & Calibration & Air & Axial & $3 / 2.67$ & - & 249 \\
\hline & Initiation & Air & Axial & 3 & 1,900 & 194 \\
\hline
\end{tabular}

rich ones. Kerosene was modeled as a chemical compound with the formula $\mathrm{C}_{12} \mathrm{H}_{23}$. The results of the calculations are shown in Fig. 5a, b. The effect of the initial temperature of the mixture on the CJ (Chapman-Jouguet) parameters was also calculated. Figure $5 \mathrm{c}$,d shows only a slight decrease in detonation velocity with increasing temperature, whereas the increase in temperature of $200 \mathrm{~K}$ resulted in almost twice the maximum pressure decrease. Such calculations were helpful in describing the results of individual experiments.

Figure 6 shows the comparison of pressure histories for shock waves and detonation waves. A shock wave was generated by the initiator filled with stoichiometric acetyleneoxygen mixture with an initial pressure of 3 bar. The initiator generates, in a $24.5 \mathrm{~mm}$ diameter test tube, a shock wave with a velocity of $875 \mathrm{~m} / \mathrm{s}$ (Mach 2.38 approx.) and post-shock pressure of about 5.5 bar. Detonation waves (red and green curves in Fig. 6) propagate in a kerosene-oxygen mixture with the calculated CJ velocity value of $2019 \mathrm{~m} / \mathrm{s}$ and mea- sured velocity of $1886 \mathrm{~m} / \mathrm{s}$ (the velocity deficit was observed for heterogeneous detonation by, for example, Nicholls et al. [25]). Comparison of these two pressure histories and velocities was used to determine if it was a shock wave or detonation. In these research stand conditions, where the test tube wall temperature reaches about $200^{\circ} \mathrm{C}$ for several hours, the use of ion probes was not fully possible. The insulation material used in the ion sensor electrode melted, making its use impossible.

An additional method of distinguishing shock waves and detonation must be taken into account- the one based on the rise time of the pressure wave (shock or detonation) recorded by the pressure sensors. For a rise time of up to $5 \mu \mathrm{s}$, and for a propagation velocity close to the CJ value, the wave was classified as a detonation. For a rise time above $10 \mu \mathrm{s}$ and a propagation velocity below $50 \%$ of the CJ value, the wave was classified as a shock wave (see graph on the upper part of Fig. 6). 

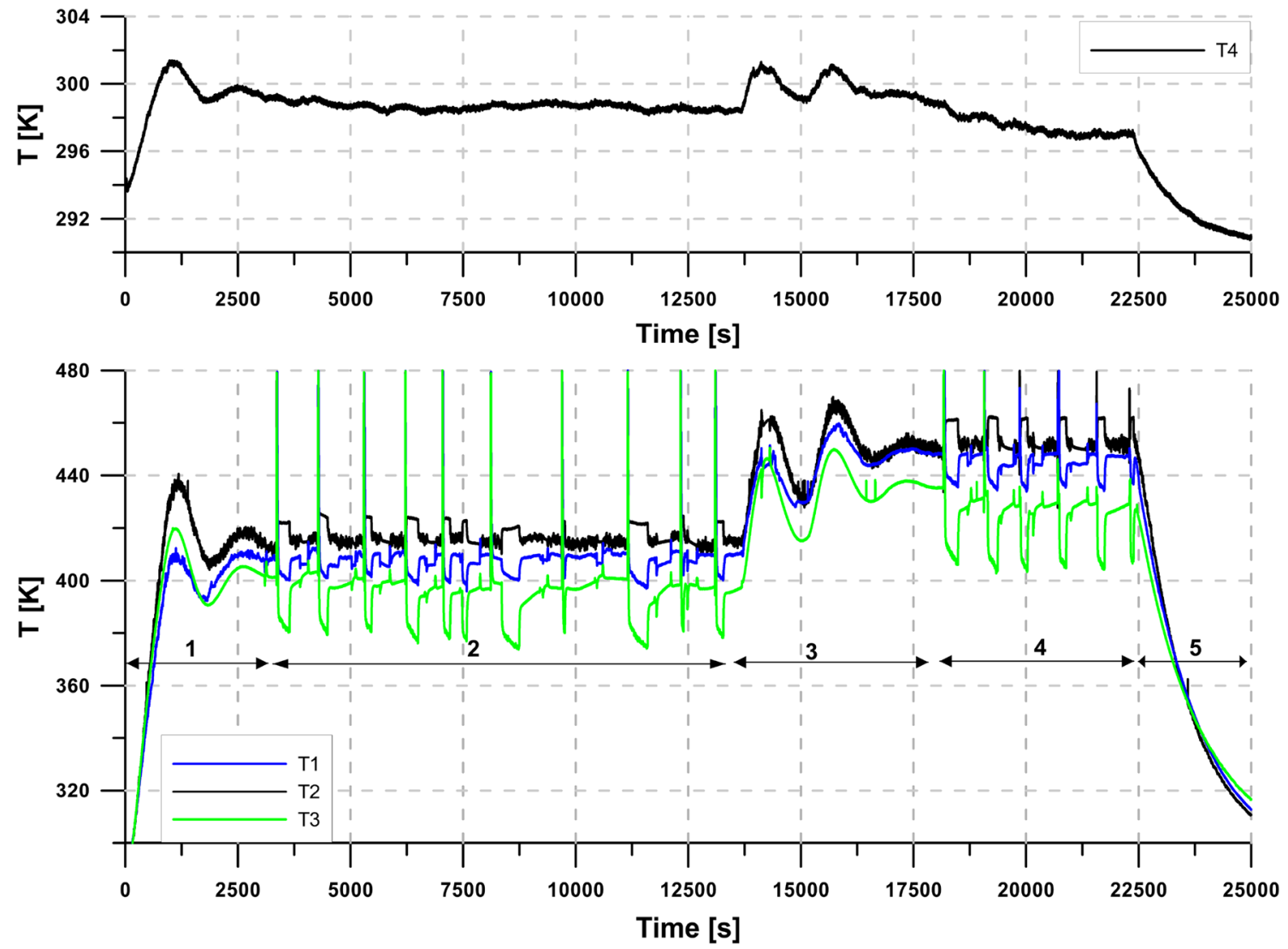

Fig. 4 The temperature histories in the test facility; results for a $\phi 44$ $\mathrm{mm}$ tube (case from 06-05-2011): $\mathrm{T}_{1}$ upper thermocouple; $\mathrm{T}_{2}$ middle thermocouple; $\mathrm{T}_{3}$ bottom thermocouple; $\mathrm{T}_{4}$ cooling water temperature.

\subsection{The tube with internal diameter of $24.5 \mathrm{~mm}$}

The study began with oxygen as the oxidizer for the smallest tube diameter of $24.5 \mathrm{~mm}$. The choice of this value was dictated by the width of the detonation chamber obtained from previous research on rotating detonation using hydrogen as the fuel and air as the oxidizer [26]. Measurements in the smallest tube were conducted with only two pressure sensors, located about $500 \mathrm{~mm}$ from each other. First, the calibration test was carried out (the shock wave generated by the initiator) for a tube filled only with oxidizer. In each graph (Figs. 7, 8, 9, 10) time zero corresponds to the start of the experiment. The moment of detonation initiation is different for different cases because three experimental parameters were changed: kerosene injection time delay, injection time and delay time between the end of kerosene injection and the initiation of the mixture in the initiator. Figure $7 \mathrm{a}$ shows the pressure history in the tube during the propagation of the shock wave generated by the initiator. The first sensor is placed at a distance of $450 \mathrm{~mm}$ from the top end of the tube and $350 \mathrm{~mm}$ from the connection place of the initiator and the main tube. It records the incident wave and the wave reflected from the upper end of the tube. When
Test time period: 1 heating and stabilisation of temperature, 2 stable temperature case 1,3 changing tube temperature, 4 stable temperature case 2, 5 cooling tube

the wave reaches the second sensor and the lower end of the tube it is reflected and moves towards the upper end. The process repeats itself more than ten times until the energy of the shock wave is totally dissipated. By measuring the wave arrival time, and knowing the distance between the transducers, the velocity of the shock wave generated by the initiator can be calculated. For an initial pressure of 1 bar in the tube and an initial pressure of 3 bar for the mixture in the initiator, the velocity of the shock wave was found to be about 870 $\mathrm{m} / \mathrm{s}$.

Figure $7 \mathrm{~b}$ shows the pressure history for the direct initiation of detonation for a pure oxygen and kerosene mixture. The velocity of the detonation wave was found to be equal to $1886 \mathrm{~m} / \mathrm{s}$. Figure $7 \mathrm{c}-\mathrm{e}$ corresponds to the direct initiation of detonation for decreasing fractions of oxygen in the oxidizer (up to $70 \%$ vol. $\mathrm{O}_{2}$ ), and for decreasing energies of initiation (up to pressures of 1 bar in the initiator). Results of further tests presented in Fig. $7 \mathrm{f}-\mathrm{h}$ indicate that a greater reduction in the $\mathrm{O}_{2}$ fraction, down to $50 \%$ and lower, makes direct initiation impossible despite the higher energy of the initiator. In most of these cases, the initiation of detonation occurred only in the reflected wave, where the local pressure increased by approximately 5 bar. 

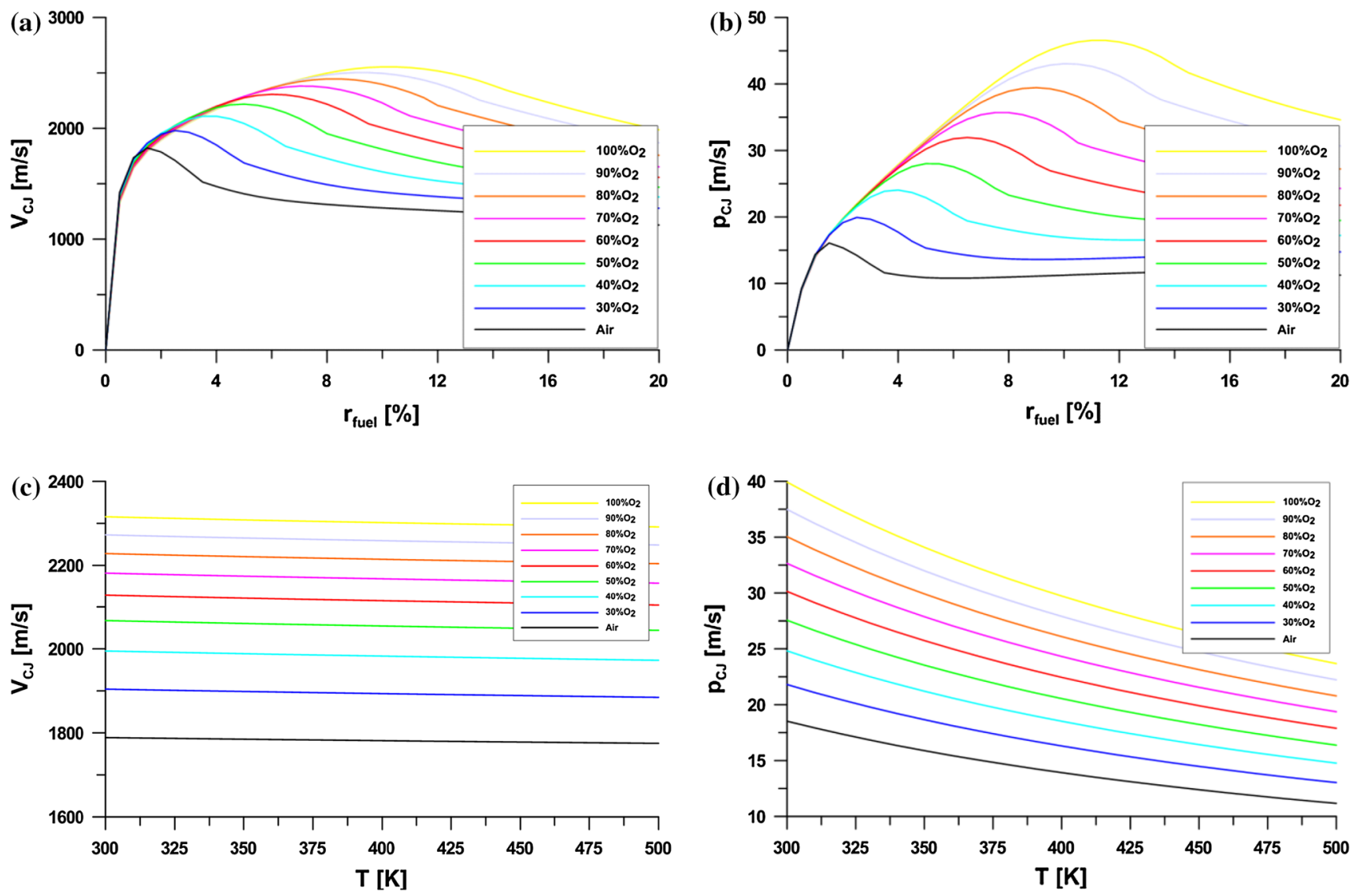

Fig. 5 Results of the theoretical calculation of the CJ values (velocity and pressure): $\mathbf{a}, \mathbf{b}$ as a function of composition of the mixture for different oxidizers; $\mathbf{c}, \mathbf{d}$ as a function of the initial temperature for the stoichiometric mixture

Moreover, the measured detonation wave velocity ranged $1,200-1,600 \mathrm{~m} / \mathrm{s}$, which may suggest that a part of kerosene evaporated, reacted or settled on the walls of the tube (the heaviest fractions) during passage through the incident wave. The values of the oxygen fraction in the oxidizer, for which there is direct initiation of detonation in the tube, are confirmed by the results obtained by Bykovskii and Vedernikov [10], who obtained detonation for the oxidizer in the form of a 1:1 mixture of pure oxygen and nitrogen in a channel with a width of $16.5 \mathrm{~mm}$, using $0.2 \mathrm{~g}$ of explosive material as the initiator.

\subsection{The tube with internal diameter of $34.7 \mathrm{~mm}$}

The next geometry tested was a tube with a diameter of 34.7 $\mathrm{mm}$. The first experiment aimed to determine the velocity of the shock wave generated by the initiator. The resulting value of $740 \mathrm{~m} / \mathrm{s}$ is about $100 \mathrm{~m} / \mathrm{s}$ lower than the velocity obtained for the previous tube, despite higher initial pressure (compare cases 80 and 39 from Table 3 ) in the initiator (Fig. 8a). Figure 8b shows the direct initiation of detonation for the injection of liquid kerosene to an oxidizer composed of $60 \%$ oxygen and $40 \%$ nitrogen. Unfortunately, fur- ther reduction of the oxygen content in the oxidizer to $50 \%$ (Fig. 8c) resulted in initiation, but only in the reflected waves at some distance from the end of the tube. Detailed analysis of the pressure histories, especially those recorded by the first sensor (see time moments around $1.9908 \mathrm{~s}$ ), shows that there is an increase in pressure (to approximately 10-12 bar) after the shock wave passes. This can be explained by the existence of some amount of evaporated light kerosene fractions around the first sensor (about half way down the tube), which took part in the burning after the shock wave had passed. However, the energy of the shock wave and the amount of vaporized kerosene was too small to be able to initiate a detonation.

Figure $8 \mathrm{~d}$ shows the case in which self-ignition occurred before the initiation impulse. It was caused by the overly high temperature locally (about 480-485 K) of the oxidizer (oxygen content in the oxidizer $-50 \%$ ). Figure 8e shows the results of the test, where the oxygen content was decreased to $40 \%$. The shock wave generated by the initiator has too low energy to initiate detonation, even after reflection from the ends of the tube. The wave reflected several times, losing energy. About $100 \mathrm{~ms}$ after the shock wave was generated in the initiator, the kerosene evaporated in significant quantities 


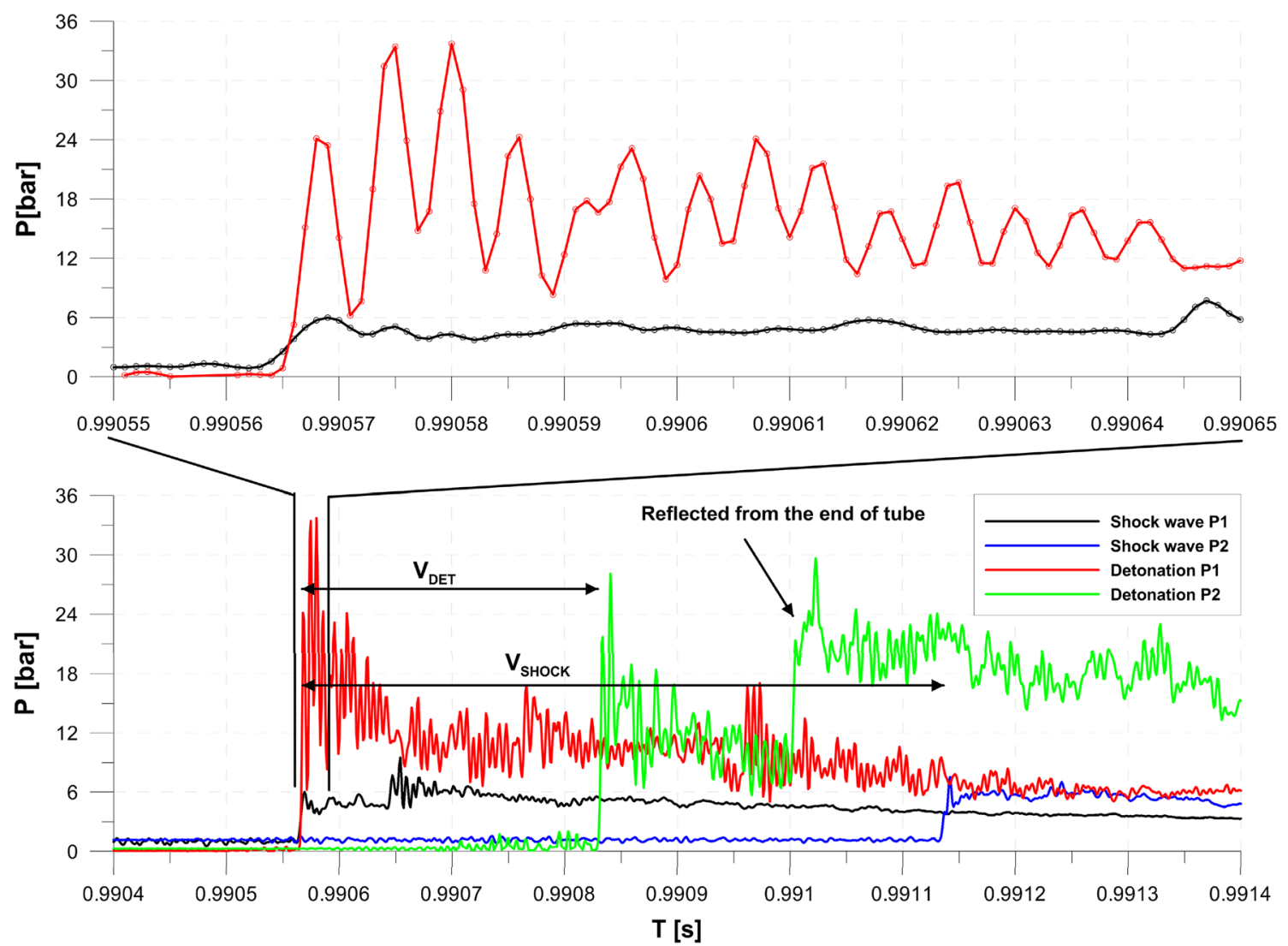

Fig. 6 Comparison of shock and detonation waves from experiments: measured values $\mathrm{V}_{\text {shock }}=875 \mathrm{~m} / \mathrm{s}, \mathrm{V}_{\text {det }}=1,886 \mathrm{~m} / \mathrm{s}$; calculated values $\mathrm{V}_{\mathrm{CJ}}=2,019 \mathrm{~m} / \mathrm{s}, \mathrm{p}_{\mathrm{CJ}}=25.2$ bar. The upper part of the figure

(droplets were also broken down by the propagating shock wave) and there was self-ignition from the hot walls of the tube. This phenomenon was observed for the temperature in the tube close to the ignition temperature of kerosene, which corresponded to the tube wall temperature of about $470 \mathrm{~K}$.

\subsection{The tube with internal diameter of $44 \mathrm{~mm}$}

The tube with an internal diameter of $44 \mathrm{~mm}$ was investigated for the initiation of detonation. A preliminary experiment was performed to check the velocity of the shock wave generated by the same initiator as in the previous cases. The initiator was installed perpendicular to the axis of the tube at a distance of $100 \mathrm{~mm}$ from the top end of the tube (as in the previous cases). As expected, the shock wave generated in the tube was weaker as a result of the increased volume of the test tube and, consequently, a stronger expansion of the initiation gases inside the test tube. An additional pressure sensor was installed in the tube, enabling determination of the value of shock wave velocity at two successive locations and, therefore, increasing the reliability of the measurements. The shock wave velocity was found to be about shows a narrow interval of the pressure history corresponding to the moment when the detonation passes the pressure sensor

$580 \mathrm{~m} / \mathrm{s}$ for an initial pressure inside the initiator of 3 bar (Fig. 9a).

Figure $9 \mathrm{~b}$ shows that direct initiation for an oxidizer containing $40 \%$ oxygen as in the previous tube $(35.7 \mathrm{~mm}$ diameter) was not possible. Further reduction of oxygen in the mixture to $30 \%$ caused a similar effect as in the previous tube: no initiation; only the passage of the shock wave from the initiator through the test mixture was observed (see Fig. 9c). To check the possibility of initiating detonation in such geometry, the initiator energy was increased significantly. This was done by increasing the diameter of the initiator to the tube diameter, shortening its length to $65 \mathrm{~mm}$ and fitting it in the axial position at the lower end of the tube. The ratio of tube to initiator volume was reduced from approximately 45 to 16 . Both volumes were separated by a plastic membrane with a thickness of $0.1 \mathrm{~mm}$. Figure $9 \mathrm{~d}$ shows the shock wave generated by the new initiator. As can be seen, it was two times faster, and increased the pressure by a factor of 2-3 compared to the case with a smaller, perpendicular initiator. Posterior experiments confirmed the desirability of modifying the initiator (Fig. 9e, f). They were carried out with the use of air as the oxidizer. The direct initiation of detonation with a short delay time between injection and ignition was obtained. 

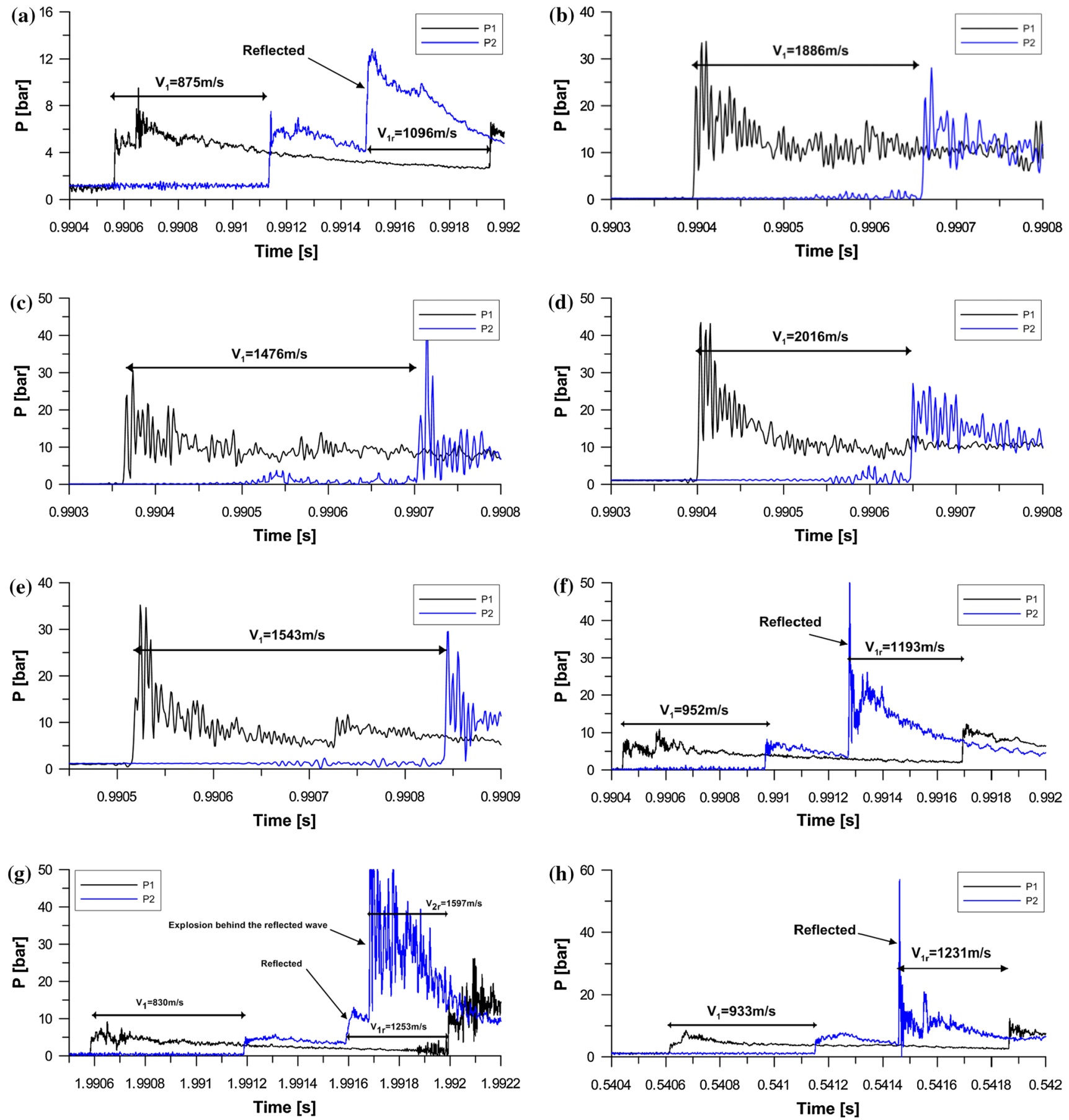

Fig. 7 Experimental results for $24.5 \mathrm{~mm}$ tube, initial pressure 1 bar, mean temperature $433 \mathrm{~K}$ : a case 39 ; $\mathbf{b}$ direct initiation-case 25 ; $\mathbf{c}$ direct initiation-case 29; $\mathbf{d}$ direct initiation—case 33; e direct initiation-

\subsection{The tube with internal diameter of $55 \mathrm{~mm}$}

The final tube studied experimentally was a tube with an internal diameter of $55 \mathrm{~mm}$. The tests were conducted for three sizes of initiator. Two initiators were transversely

case $38 ; \mathbf{f}$ explosion behind the reflected wave in partly reacted mixture — case 42; g explosion behind the reflected shock wave-case 44; $\mathbf{h}$ explosion behind the reflected shock wave-case 67

located with respect to the axis of the tube and another one was positioned along the axis of the initiator at the end of the tube. Figure 10a shows the presence of the shock wave generated by the small, perpendicular initiator, with a velocity of $520 \mathrm{~m} / \mathrm{s}$. 

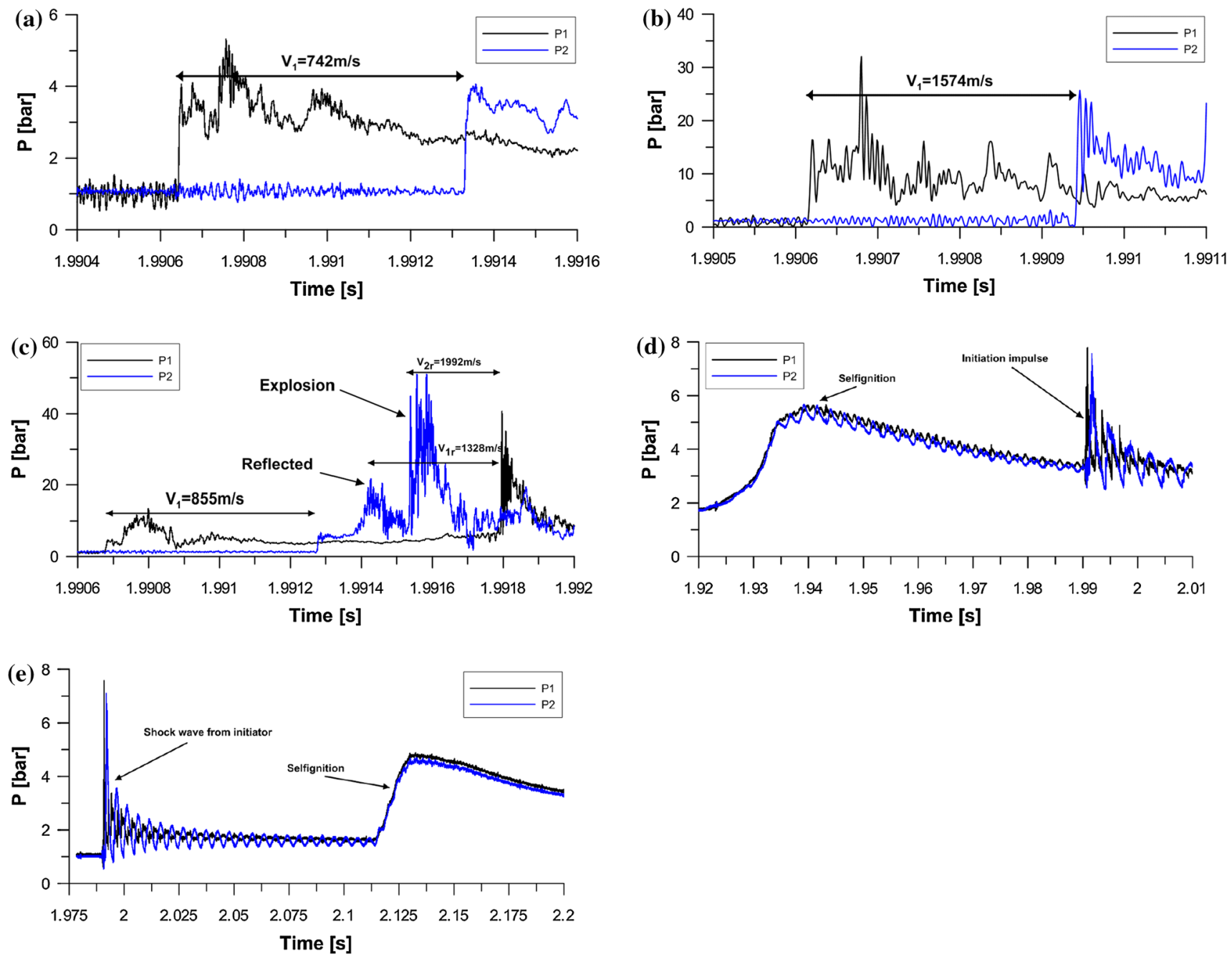

Fig. 8 Experimental results for $35.7 \mathrm{~mm}$ tube; initial pressure $1 \mathrm{bar}$, mean temperature $433 \mathrm{~K}$ : a case 80 ; $\mathbf{b}$ direct initiation-case 73 ; $\mathbf{c}$ initiation behind the reflected shock wave-case 75; d self-ignition (for

The next graph (Fig. 10b) demonstrates the initiation of detonation for oxygen content of $30 \%$ in the oxidizer. As can be seen, the initiation of detonation was not achieved and the shock wave velocity was increased by about 100 $\mathrm{m} / \mathrm{s}$ compared to the situation where there was no fuel injection (Fig. 10a). This can be explained by the combustion of a small amount of vaporized, mostly volatile, fractions of kerosene. Figure 10c shows the propagation of the shock wave generated by the second initiator (perpendicular to a larger volume); the resulting wave velocity was about 760 $\mathrm{m} / \mathrm{s}$. As shown in the next graph (Fig. 10d), the initiator generates enough energy to initiate detonation at $30 \%$ oxygen content in the oxidizer. Unfortunately, in subsequent experiments (using air as an oxidizer) initiation was not achieved.

Figure 10e shows the third initiator (axial) with the diameter equal to the tube diameter, which generates a shock wave

this case, tube temperature locally approaches $485 \mathrm{~K}$ )—case 98 ; e selfignition-long after the initiation impulse (tube temperature locally approaches $470 \mathrm{~K}$ )—case 89

with a velocity of about $1,000-1,200 \mathrm{~m} / \mathrm{s}$. Axial assembly of the initiator allowed maximum energy to be transferred directly into the fuel-air mixture contained in the tube. Propagation of the shock wave generated by the initiator is shown in Fig. 10e. Fig. 10f demonstrates the direct initiation of detonation of the kerosene-air mixture. As shown in the presented pressure histories, only a high-energy initiator was able to directly initiate detonation in the kerosene-air mixture in such a short tube as the one used in the study.

As mentioned earlier, it was impossible to exactly determine the combustible mixture composition. The reason for this was the injection of cold kerosene: the degree of evaporation was dependent on many factors including the medium (oxidizer) temperature and the size of droplets. A part of the injected droplets passes through the entire length of the tube and settles at its cool end. 

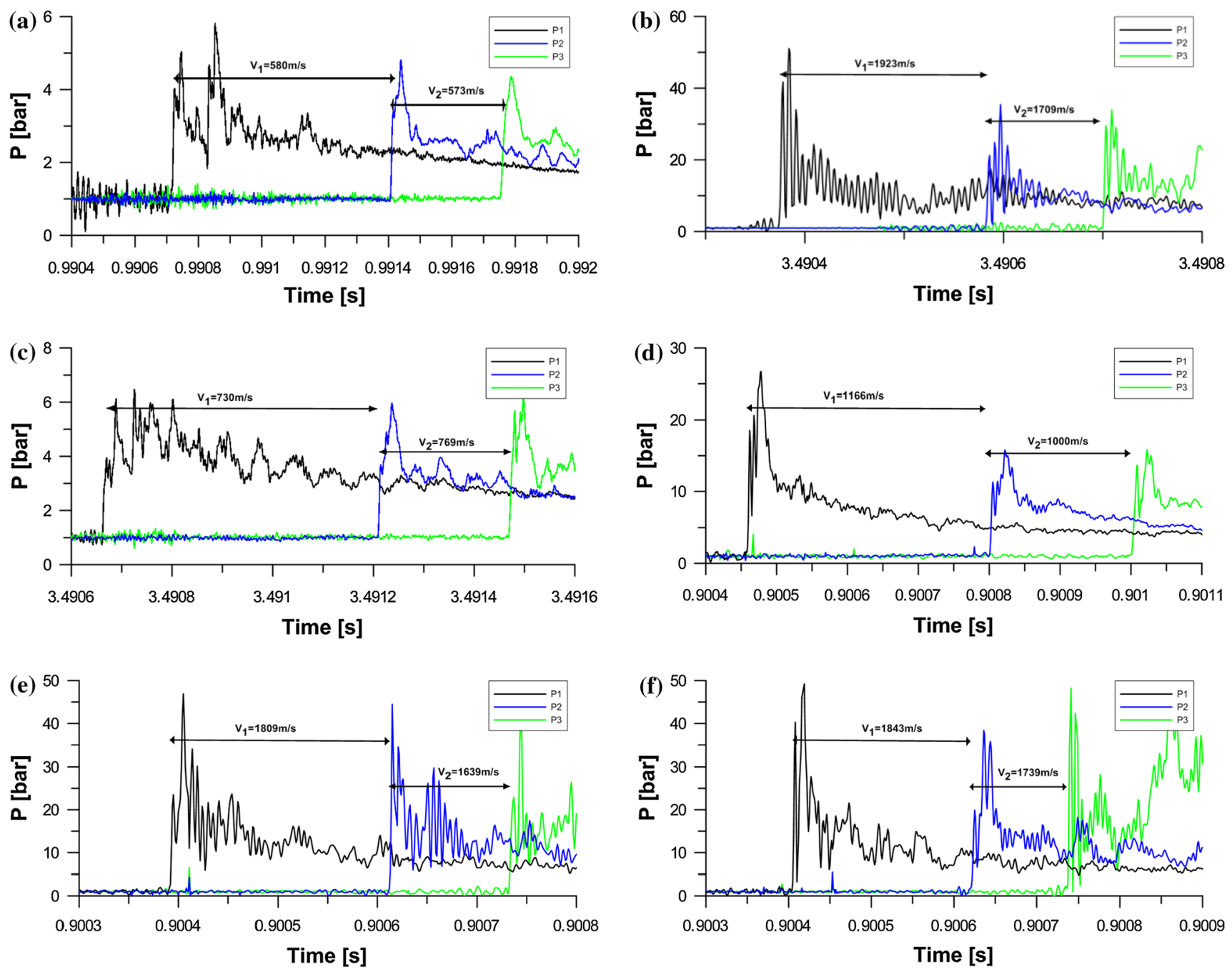

Fig. 9 Experimental results for $44 \mathrm{~mm}$ tube; initial pressure 1 bar, mean temperature 433-443 K: a case-113; b direct initiation—case 130; c no initiation-case 140; $\mathbf{d}$ case-231; e, f direct initiation-cases 232, 233

The situation is illustrated by the results of some experiments.

Figure 11 shows a comparison of the two waveforms for the tube with an inside diameter of $55 \mathrm{~mm}$ and the initiator located axially. In Fig. 11 two cases are presented. Figure 11a shows the direct initiation of detonation for a mixture with an estimated equivalence ratio of 1.82 . The resulting detonation velocity is only about $50 \mathrm{~m} / \mathrm{s}(2.6-4.3 \%)$ lower than the $\mathrm{CJ}$ value. Figure $11 \mathrm{~b}$ demonstrates the absence of initiation of detonation for a mixture with a composition having an equivalence ratio of about 1.41 . The measured velocity of detonation was found to be only $1,226-1,423 \mathrm{~m} / \mathrm{s}$ while the calculated value is $1823 \mathrm{~m} / \mathrm{s}$; the difference changes from 21 to $32 \%$. In addition, the velocity between the two measurements for this experiment decreases by about $200 \mathrm{~m} / \mathrm{s}$, which indicates that there was a strong shock wave that was additionally fed by the oxidation of a part of the fuel. There are two possible explanations for this. The first is that there was very small amount of vaporized fuel and therefore the actual composition of the mixture was much leaner than the results of the measurements indicated (from the flow rate of the fuel injector). The second explanation for the result might be the assumption that all the kerosene evaporate and the ignition of the mixture needs more energy, whereas in both cases the same energy is supplied.

Figure 12 summarizes all the experimental results obtained for the cases described above: direct initiation, initiation by reflected wave and no initiation. The graph is presented in the coordinates of the amount of oxygen in the oxidizer and the diameter of the tube. Different energies of the initiator are marked with different colours. The existence of a quasi-linear correlation between the diameter of the tubes and the oxygen content can be clearly seen. Additionally, the minimum energy required to obtain detonation initiation for a given tube diameter and given oxygen content in the oxidizer can be determined. Knowledge of the value of this energy and the 

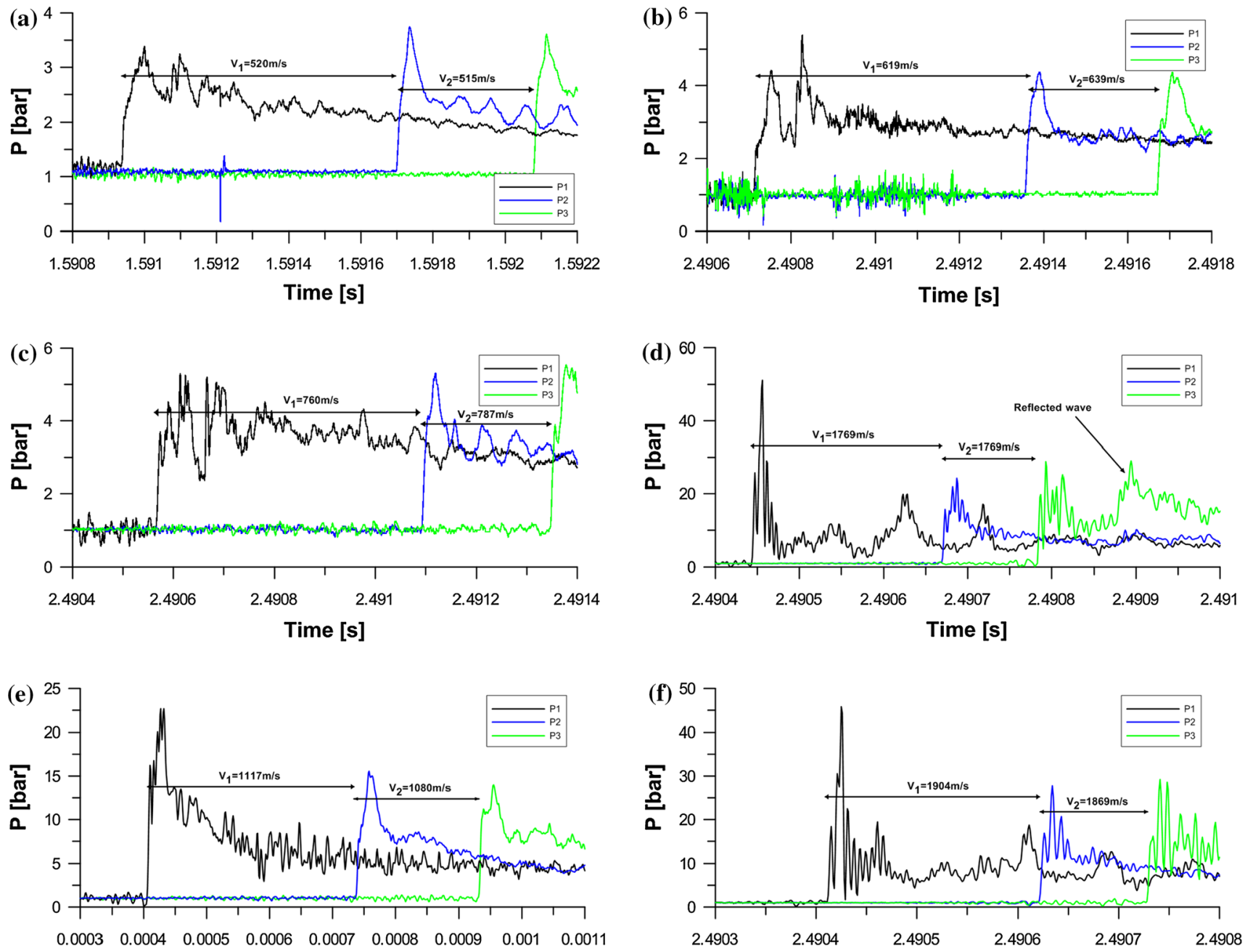

Time [s]

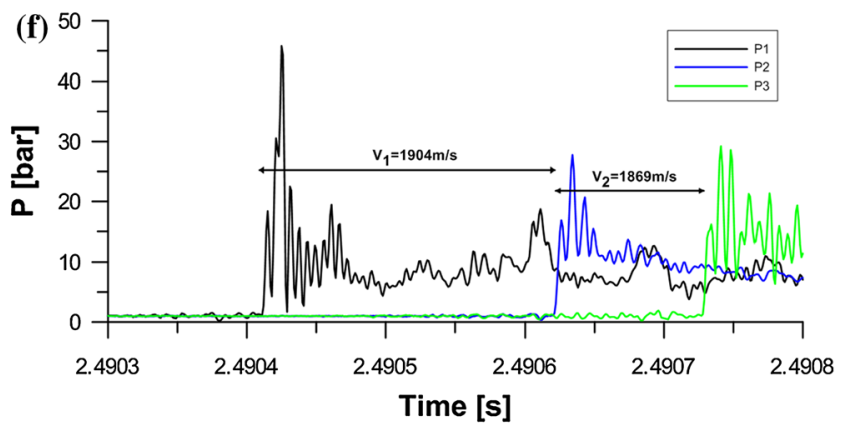

Fig. 10 Experimental results for $55 \mathrm{~mm}$ tube; initial pressure 1 bar, mean temperature $433 \mathrm{~K}$ : a case 253; b no initiation-case 183; c case 186; d direct initiation—case 19; e case 249; f direct initiation—case 194
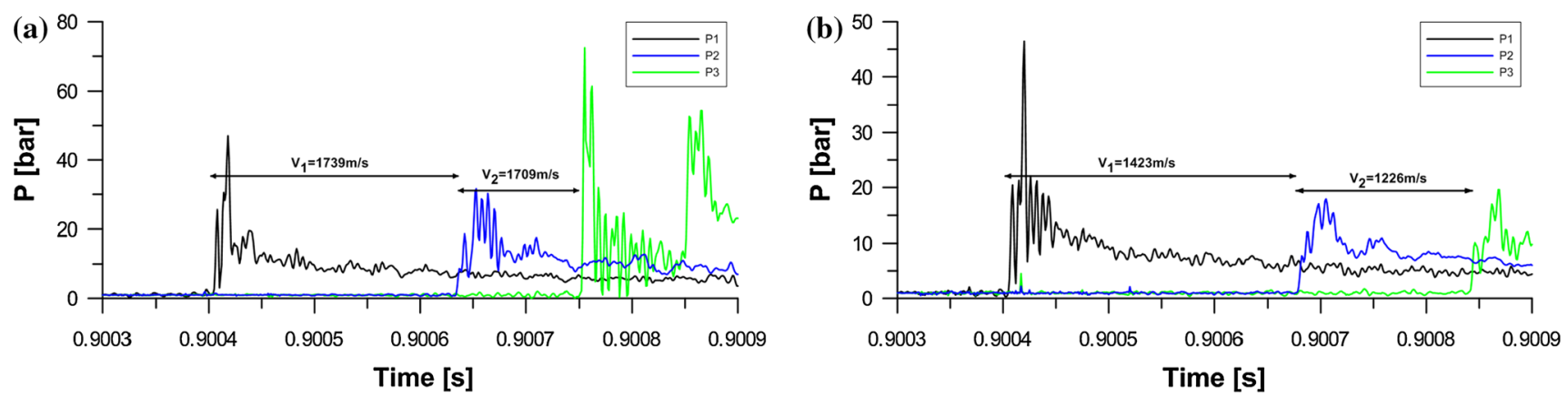

Fig. 11 Experimental results for $55 \mathrm{~mm}$ tube; initial pressure 1 bar, mean temperature $413-433 \mathrm{~K}$, axial initiator with 3 bar pressure, ignition delay $400 \mathrm{~ms}$ : a equivalence ratio $\approx 1,82 \pm 0.2, \mathrm{~V}_{\mathrm{CJ}}=1,786 \mathrm{~m} / \mathrm{s} ; \mathbf{b}$ equivalence ratio $\approx 1,41 \pm 0.2, \mathrm{~V}_{\mathrm{CJ}}=1,823 \mathrm{~m} / \mathrm{s}$

diameter of the tube will inform in practical terms the design of the geometry of the chamber in which it would be possible to initiate rotating detonation for liquid kerosene and air as the oxidizer.

\section{Summary and conclusions}

The paper presents the results of research on the initiation of detonation in a mixture of kerosene-oxidizer for $1.05 \mathrm{~m}$ long 
Fig. 12 The possibility of obtaining direct initiation of detonation as a function of oxygen in the oxidizer and the diameter of the tube (colours signify different initiators: black small, perpendicular; blue large, perpendicular and red axial)

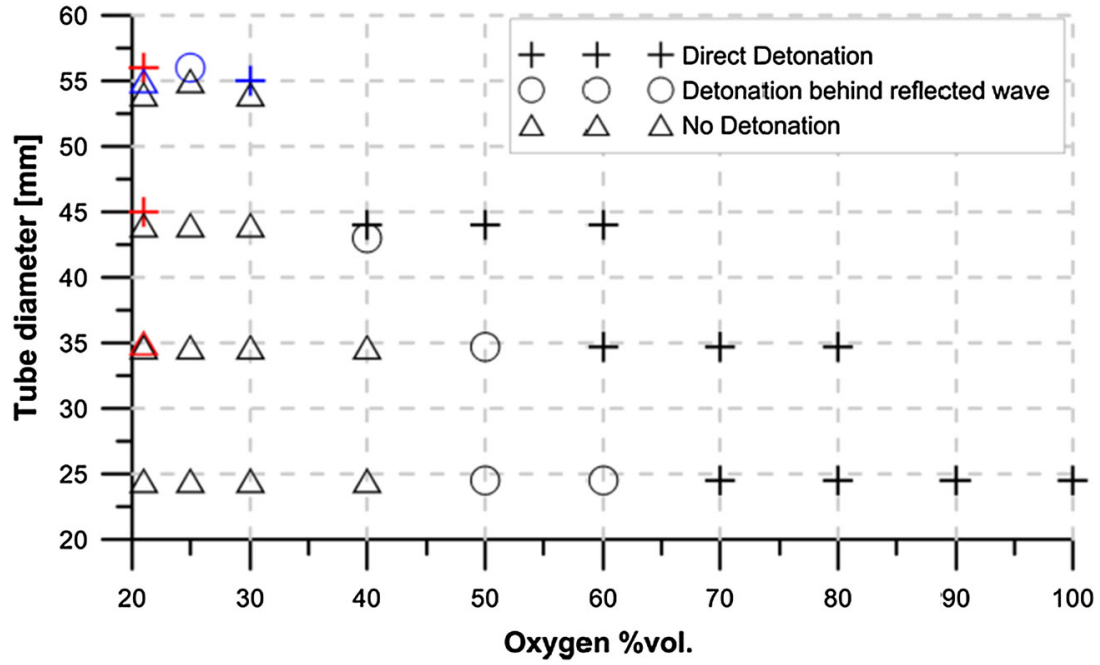

tubes with various internal diameters. The test stand was specially designed to simulate the geometry and conditions for a realistic combustion chamber. The injection of liquid fuel at a temperature of about $300 \mathrm{~K}$ was designed to simulate real conditions in the combustion chamber. The process of fragmentation of the jets of fuel and its evaporation occurred shortly after injection into the test tube, making it an even closer approximation of real conditions. This approach made it difficult to precisely determine the composition of the fueloxidizer mixture due to the lack of knowledge regarding the quantity of kerosene which evaporates before the detonation wave arrives.

Nevertheless, the approach does take into account the impact of these processes on the magnitude of the energy required to initiate the process of detonation within a very short distance. Furthermore, the location of the first pressure sensor close to the place (approximately $400 \mathrm{~mm}$ ) where the initiator connects to the research tube, enables one to determine whether or not the initiation of detonation was direct. This applies to the cases where the detonation is initiated just after the exit of the initiator. This is connected with the method adopted for determining whether there is a detonation or shock wave (e.g., see Fig. 8b). Results of studies conducted under other conditions where the fuel was pre-heated or vaporized are widely available in the literature (Schauer et al. [18], Sorin and Bauer [19], Frolov and Aksenov [21]).

The direct initiation of detonation was obtained for each test tube for different types of oxidizer (see Fig. 12). For the tube with the smallest diameter $(24.5 \mathrm{~mm})$ detonation was obtained for an oxidizer composition ranging from pure oxygen to a mixture of $70 \% \mathrm{O}_{2}+30 \% \mathrm{~N}_{2}$ using the initiator with the lowest energy $(840 \mathrm{~J})$. For the tubes with diameters of $44 \mathrm{~mm}$ and $55 \mathrm{~mm}$ direct initiation of detonation was obtained for kerosene-air mixtures. Shock waves generated by the initiator and recorded at the first pressure sensor had a velocity of about $1,200 \mathrm{~m} / \mathrm{s}$. Taking into account the dis- tance from the sensor to the entrance of the initiator and the method of shock wave generation, it can be concluded that the wave had a much higher velocity just after the entrance to the tube.

For cases where it was impossible to directly initiate detonation for a given tube diameter and composition of oxidizer (e.g., the tube with a diameter of $24.5 \mathrm{~mm}$ and an oxidizer of $50 \% \mathrm{O}_{2}+50 \% \mathrm{~N}_{2}$ ) the detonation was initiated immediately after the shock wave reflected from the end of the tube. For example, Fig. 7a shows an increase in the reflected shock wave velocity of about $200 \mathrm{~m} / \mathrm{s}$ in relation to the incident wave velocity. This velocity rise significantly increases the chances of initiating detonation. This observation indirectly confirms the observations made by Dean et al. [20]. They noted a significant decrease in activation energy when the shock wave temperature exceeded $1400 \mathrm{~K}$. Further reduction in the volume fraction of oxygen in the oxidizer causes an inability to initiate detonation in the fuel-oxidizer mixture for the same initiator energy. In addition, a further increase in the initial temperature of the oxidizer with an unchanged energy of initiator causes only self-ignition of the mixture (see Fig. 8d). In summary, these studies offer information data on the geometry of the designed detonation chamber and on what initiator must be used to effectively initiate the detonation of a heterogeneous fuel-oxidizer mixture.

Acknowledgments This work was supported by the Ministry of Science and Higher Education, Republic of Poland, project no. 838/B/T02/2009/37. The author would like to thank the MSc student Damian Iracki for his help in carrying out the experiments, and Prof. Rudolf Klemens, Dr. Arkadiusz Kobiera and Dr. Pawel Oleszczak for many fruitful and valuable discussions during the preparation of this paper.

Open Access This article is distributed under the terms of the Creative Commons Attribution License which permits any use, distribution, and reproduction in any medium, provided the original author(s) and the source are credited. 


\section{References}

1. Roy, G.D., Frolov, S.M., Borisov, A.A., Netzer, D.W.: Pulse detonation propulsion: challenges, current status, and future perspective. Progr. Energy Combust. Sci. 30, 545-672 (2004)

2. Rasheed, A., Furman, A., Dean, A.J.: Experimental investigations of an axial turbine driven by a multi-tube pulsed detonation combustor system. In: 41st AIAA/ASME/SAE/ASEE Joint Propulsion Conference \& Exhibit; Tucson, AZ; USA; 10-13 July 2005, AIAA Paper 2005-4209 (2005)

3. Voitsekhovskii, B.V., Mitrofanov, V.V., Topchiyan, M.E.: Structure of the detonation front in gases. In: Izdatielstvo SOAN SSSR, Novosibirsk (1963) (in Russian)

4. Voitsekhovskii, B.V.: Stationary detonation. Dokl. Akad. Nauk SSSR 129(6), 1254-1256 (1959)

5. Nicholls, J.A., Wilkinson, H.R., Morrison, R.B.: Intermediate detonation as a thrust producing mechanism. Jet Propul. 27(5), 534-541 (1957)

6. Bykovskii, F.A., Mitrofanov, V.V., Vedernikov, E.F.: Continuous detonation combustion of fuel-air mixtures. Combust. Explos. Shock Waves 33(3), 344-353 (1997)

7. Wolanski, P., Kindracki, J., Fujiwara, T.: An experimental study of small rotating detonation engine. In: Roy, G., Frolov, S., Sinibaldi, J. (eds.) Pulsed and Continuous Detonations, pp. 332-338. Torus Press, Moscow (2006)

8. Kindracki, J., Wolanski, P., Gut, Z.: Experimental research on the rotating detonation in gaseous fuels-oxygen mixtures. Shock Waves 21, 75-84 (2011). doi:10.1007/s00193-011-0298-y

9. Bykovskii, F.A., Zhdan, S.A., Vedernikov, E.F.: Continuous spin detonation of hydrogen-oxygen mixtures. 1: Annular cylindrical combustors. Combust. Explosion Shock Waves 44(2), 150-162 (2008)

10. Bykovskii, F.A., Vedernikov, E.F.: Continuous detonation of a subsonic flow of a propellant. Combust. Explosion Shock Waves 39(3), 323-334 (2003)

11. Bykovskii, F.A., Zhdan, S.A., Vedernikov, E.F.: Continuous spin detonation in annular combustors. Combust. Explosion Shock Waves 41(4), 449-459 (2005)

12. Bykovskii, F.A., Zhdan, S.A., Vedernikov, E.F.: Continuous spin detonation of fuel-air mixtures. Combust. Explosion Shock Waves 42(4), 463-471 (2006)

13. Vasil'ev, A.A., Mitrofanov, V.V., Topchiyan, M.E.: Detonation waves in gases. Combust. Explosion Shock Waves 23(5), 605-623 (1987)

14. Alekseev, V.I., Dorofeev, S.B., Sidorov, V.P., Chaivanov, B.B.: Experimental study of large-scale unconfined fuel spray detonations. In: Kuhl, A.L., Leyer, J.C., Borisov, A.A., Sirignano, W.A. (eds.) Progress in Astronautics and Aeronautics, voll. 154, Dynamics Aspects of Explosion Phenomena, pp. 95-104. AIAA, Washington (1993)
15. Papavassiliou, J., Makris, A., Knystautas, R., Lee, J.H.: Measurements of cellular structure in spray detonation. In: Progress in Astronautics and Aeronautics, vol. 154, pp. 148-169. American Institute of Aeronautics and Astronautics, VA (1993)

16. Kailasanath, K.: Liquid-fueled detonations in tubes. j. propul. power 22(6), 1261-1268 (2006)

17. Alekseev, V.I., Dorofeev, S.B., Sidorov, V.P.: Direct initiation of detonations in unconfined gasoline sprays. Shock Waves 6, 67-71 (1996)

18. Schauer, F.R., Miser, C.L., Tucker, K.C., Bradley, R.P., Hoke, J.L.: Detonation initiation of hydrocarbon-air mixtures in a Pulsed Detonation Engine. In: 43rd AIAA Aerospace Sciences Meeting, Reno, NV, 10-13 January 2005, AIAA Paper 2005-1343 (2005)

19. Sorin, R., Bauer, P., Desbordes, D.: Detonability of THDCPD-exoair mixtures. Shock Waves 17, 363-369 (2008)

20. Dean, A.J., Penyazkov, O.G., Sevruk, K.L., Varatharajan, B.: Ignition of aviation kerosene at high temperatures. In: Proceedings 20th International Colloquium on Dynamics of Explosions and Reactive Systems (ICDERS), Montreal, Canada, 31 July-5 August 2005 (2005)

21. Frolov, S.M., Aksenov, V.S.: Deflagration-to-detonation transition in a kerosene-air mixture. Doklady Phys. Chem. 416(1), 261-264 (2007). doi:10.1134/S0012501607090072

22. Imbert, B., Catoire, L., Chaumeix, N., Dupre, G., Paillard, C. Effect of two additives $\left(\mathrm{CH}_{3} \mathrm{NO}_{2}\right.$ and $\left.\mathrm{H}_{2} \mathrm{O}_{2}\right)$ on the detonation properties of gaseous stoichiometric $n-\mathrm{C}_{7} \mathrm{H}_{16} / \mathrm{O}_{2}$ mixtures. In: Proceedings 20th International Colloquium on Dynamics of Explosions and Reactive Systems (ICDERS), Montreal, Canada, 31 July5 August 2005 (2005)

23. Austin, J.M., Shepherd, J.E.: Detonations in hydrocarbon fuel blends. Combust. Flame 132((1-2)), 73-90 (2003)

24. Akbar, R., Thibault, P.A., Harris, P.G., Lussier, L.-S., Zhang, F., Murray, S.B., Gerrard, K.: Detonation properties of unsensitized and sensitized JP-10 and Jet-A fuels in air for pulse detonation engines. AIAA Paper 2000-3592 (2000)

25. Wen, C.-S., Chung, K.-M., Lai, W.-H.: Detonation initiation of JP8 -oxygen mixtures at different initial temperatures. Shock Waves 22, 477-482 (2012). doi:10.1007/s00193-012-0398-3

26. Kindracki, J., Kobiera, A., Wolanski, P., Gut, Z., Folusiak, M., Swiderski, K.: Experimental and numerical research on the rotating detonation engine in hydrogen-air mixtures. In: Frolov, S. (ed.) Advances in Propulsion Physics. Torus Press, Moscow (2011)

27. Reynolds, W.C.: The element potential method for chemical equilibrium analysis: implementation in the interactive program STANJAN, Stanford University Report (1986)

28. Reynolds, W.C.: STANJAN-Interactive computer programs for chemical equilibrium analysis. Stanford University, Palo Alto, California (1990) 